\title{
CULTURA POLIITICA: UN INVENTARIO BIBLIOGRÁFICO (1985-2005)
}

\section{POLITICAL CULTURE: A BIBLIOGRAPHICAL REPORT (1985-2005)}

\section{Antonio Murga Frassinetti*}

RESUMEN

Este inventario bibliográfico comenta poco más de sesenta títulos —entre libros y artículos - que representan algunas de las aportaciones teóricas, metodológicas y empíricas más relevantes producidas en el campo de la cultura política durante los últimos veinticinco años. Los estudios empíricos refieren a las democracias industriales avanzadas, a las sociedades ex socialistas y a algunos países asiáticos. Una bibliografía sobre la cultura política latinoamericana, cada vez más abundante, es parte de un reporte especial.

PALABRAS CLAVE: CULTURA POLÍTICA * VALORES POLÍTICOS * APOYO POLÍTICO * DESAFECCIÓN POLÍTICA * SENTIMIENTOS ANTIPARTIDISTAS

\section{ABSTRACT}

This bibliographical report comments more than sixty titles -books and articles. The titles are some of the most important theoretical, methodological and empirical contributions in the field of political culture. All titles were published along the last twenty years. The case studies are about the advanced industrial democracies, the ex communist societies and the Far East.

KEYWORDS: POLITICAL CULTURE * POLITICAL VALUES * POLITICAL SUPPORT * POLITICAL DISAFFECTION * ANTY PARTY SENTIMENTS

Departamento de Sociología de la Universidad Autónoma Metropolitana-Unidad Iztapalapa, México. almf@xanum.uam.mx 


\section{INVENTARIO BIBLIOGRÁFICO}

Hace poco menos de dos décadas, Ronald Inglehart (1991, cap. 1) observó que los estudios sobre cultura política (CP) habían iniciado una nueva etapa, la del renacimiento intelectual ${ }^{1}$. La abundante bibliografía teórica, metodológica y empírica publicada a partir de los años ochenta, constituye el referente empírico más inmediato de ese renacimiento. Esta observación ha planteado una gama diversa de interrogantes; entre ellas, por ejemplo, la referida a los factores sociales, políticos e intelectuales asociados a ese renacimiento, el perfil teórico y metodológico que caracteriza a la nueva etapa, las problemáticas centrales o los ejes analíticos de la nueva investigación, las dimensiones, conceptos y variables que vertebran el análisis de la cultura política actual, las innovaciones metodológicas e instrumentales generadas por este movimiento intelectual, los hallazgos empíricos más significativos de la nueva producción bibliográfica, etc. El propósito de esta introducción no es dar respuesta a cada una de estas preguntas; más bien interesa comentar algunas de las contribuciones teóricas y empíricas más influyentes en el renacimiento de los estudios sobre cultura política.

\section{EL RENACIMIENTO}

En términos generales, los estudiosos han subrayado que entrados los años ochenta, el estudio de la CP empezó a ganar otra vez vitalidad y dinamismo teórico. Muchas son las

1 Grosso modo, los estudios de cultura política han pasado por tres etapas. La primera inicia en los años sesenta, con la publicación de la obra fundacional de Gabriel Almond \& Sydney Verba (The Civic Culture: political attitudes and democracy in five nations, Princeton University Press, 1963) y la aparición multiplicada de estudios sobre la CP; la segunda inicia en los años setenta y está signada por la fuerte oleada crítica que destacó las debilidades y limitaciones teóricas, metodológicas y empíricas de la propuesta de Almond \& Verba; por último, la tercera etapa que inicia en los años ochenta es denominada como el renacimiento de los estudios de cultura política. razones (Dalton, 2006); destaquemos dos de ellas. Primero, la erosión de la confianza en los actores políticos, la declinación de la confian$z a$ en las instituciones $y$ la insatisfacción con el funcionamiento del sistema político en los países industriales desarrollados pusieron en duda la validez de propuesta clásica (Almond \& Verba): la cultura cívica y sus funciones en el mantenimiento de los sistemas democráticos. La segunda razón se vincula con el debilitamiento y caída de los gobiernos autoritarios a la par del ascenso de nuevas formas de gobierno democrático, cuasi democrático, democracias limitadas, de baja intensidad, iliberales, no liberales, restrictivas, delegativas, etc. (Huntington, O'Donnell, Przeworski).

Esta ola democratizadora - como la denominó Samuel Huntington ${ }^{2}$ - produjo numerosas explicaciones ${ }^{3}$. Una corriente destacó que la transición democrática fue el resultado de las preferencias estratégicas de las elites políticas; según esta perspectiva, la cultura política no tuvo ninguna influencia importante en los procesos democratizadores. De acuerdo con un reconocido estudioso, "la amenaza para los regímenes autoritarios no procede del desmoronamiento de su legitimidad, sino de la organización de una contrahegemonía (es decir), de que existan proyectos colectivos para un futuro alternativo"4. Y de acuerdo con otro,

2 S. P. Huntignton. La Tercera Ola: la democratización a finales del siglo $X X$. Barcelona: Ediciones Paidós, 1994.

3 Algunos trabajos referenciales que analizan las cuestiones centrales de la bibliografía sobre la democratización del último cuarto del siglo veinte son los artículos de Renske Doorenspleet. "The structural context of recent transitions to democracy". European Journal of Political Research 2. 2004: 309-335; Barbara Geddes. "O qué sabemos sobre democratizacao depois de 20 anos?" Opiniao Pública 2. 2001; Doh Shull Shin. "On the third wave of democratization: a synthesis and evaluation of recent theory and research". World Politics 1. 1994: 135-170.

4 A. Przeworski. Democracia y Mercado; reformas políticas y económicas en la Europa del Este y América Latina. Cambridge University Press, 1995: 92 y ss. 
"la dinámica de la transición gira en torno a interacciones estratégicas y acuerdos tentativos entre los actores (...) Desde este punto de vista, la consolidación de un régimen ocurre cuando las clases sociales y grupos políticos aceptan una serie de reglas formales o acuerdos informales que determina el 'quién se queda con qué, dónde, cuándo y cómo’ de la política”5.

Otra corriente interpretativa subrayó que la cultura política constituye una "variable estratégica" (Inglehart, 1991) en la transición y la consolidación democrática. En efecto, a partir de la obra clásica de Almond \& Verba ${ }^{6}$, la hipótesis central ha planteado que las actitudes prodemocráticas de los ciudadanos propician la instauración en unos casos y el mantenimiento en otros, de las instituciones democráticas. En tal perspectiva, las nuevas contribuciones afirman que las democracias "requieren una cultura que la sustente, es decir, la aceptación de los ciudadanos y de las elites políticas de ciertos principios plasmados en la libertad de expresión, de información, de culto, en los derechos de los partidos de oposición, en el imperio de la ley y los derechos humanos, entre otros"7. En otras palabras, el sistema democrático "depende de un sentimiento profundamente arraigado de legitimidad entre el público" (Inglehart, 2001: 272).

Esta segunda interpretación generó un gran atractivo intelectual y una nueva generación de estudiosos, a un nivel mundial ${ }^{8}$, volcó

T. L. Karl. "Dilemas de la democratización en América Latina". J. L. Reyna (comp.). América Latina a fines del siglo. México, CNCA-FCE, 1995: 442-443.

S.M. Lipset. "Repensando los requisitos sociales de la democracia". La Política: Revista de Estudios sobre el Estado y la sociedad 2. 1996: 55-58. sus esfuerzos analíticos al estudio de la CP. Entendida como un conjunto multidimensional es decir, valores, actitudes, ideologías y evaluaciones ciudadanas del sistema político, el régimen, las instituciones y de ellos mismos como ciudadanos, además de la participación política $^{9}$, la nueva generación de estudiosos la denominan como actitudes democráticas (Weil, 1993), actitudes políticas (Abramson, 1987), actitudes públicas (McClosky \& Zaller, 1994), concepciones populares (Barnes \& Simon, 1998), cultura democrática (Fuchs, 1999), cultura prodemocrática (Inglehart, 2006), cultura política contemporánea (Gibbins, 1986), cultura política posmoderna (Topf, 1988), nueva cultura política (Clark, 1998), etc.

Al mismo tiempo, la nueva generación aportó numerosas propuestas teóricas (Norris, 1999; Dalton, 2006), construyó nuevas dimensiones teóricas, variables e indicadores empíricos, diseñó nuevos instrumentos para la recolección de datos con aplicación multinacional ${ }^{10}$, y recuperó en unos casos y desarrolló en otros, viejas y nuevas temáticas. Para citar unas

Ricardo Córdova (El Salvador), Dinorah Aspuru (Guatemala), Julio Carrión (Perú); Carmen Haretche y Lucía Selios (Uruguay) y Damarys Canache (Venezuela). En el caso mexicano destacan las contribuciones, entre otras, de Miguel Basañez, José Antonio Crespo, Víctor Manuel Durand, Anna María Fernández, Julia Flores, Yolanda Meyenberg, Alejandro Moreno, Pablo Parás.

V. M. Durand. Ciudadanía y cultura política: México 1993-2001. México: Siglo XXI, 2004.

Entre estos nuevos instrumentos destacan el Eurobarómetro que se levanta entre los países miembros de la Comunidad Europea desde los años setenta, la Encuesta Mundial de Valores (EMV) que inició en 1981-1982 y aplicó en 82 países el año 2000; el Latinobarómetro que se recoge en 17 países latinoamericanos desde 1995; el New Democracies Barometer que se aplica en un grupo de nueve países ex socialistas de la Europa central y oriental. Más recientemente, en 2002-2003 inició la Encuesta Social Europea, apoyada por la European Science Foundation, y el Proyecto de Opinión Pública de América Latina, más conocido como $L A P O P$ (por sus siglas en inglés). 
pocas, mencionemos el apoyo democrático (Evans, 1995), apoyo político (Dalton, 2004) y/o apoyo popular (Rose, Mishler \& Haerpfer, 1998), el asociacionismo político (Morales, 2006), la comunidad política (Westle, 1989), la confianza $y / 0$ desconfianza institucional (Hibbing \& Theiss-Morse, 1995), la confianza interpersonal (Inglehart, 1991), el conocimiento político (Delli Carpini \& Keeter, 1989), la desafección política (Torcal, 2001), el descontento (Craig, 1993), la eficacia política (Gabriel, Hayes \& Bean, 1993), la identificación partidista (Clarke \& Stewart, 1998), el interés político (Gabriel \& van Deth, 1998), la legitimidad democrática (Montero \& Morlino, 1993), la participación política (Barnes \& Kaase, 1980), la satisfacción democrática (Fuchs 1993, Fuchs et ál., 1998), los sentimientos partidistas (Abramson, 1987) y antipartidistas (Torcal, Montero \& Gunter, 2003), la tolerancia política (Sullivan et ál, 1981), los valores democráticos (Thomassen, 1998), políticos (Miller \& Reisinger) y posmaterialistas (Inglehart, 1991, 2000), etc.

\section{ALGUNOS PROBLEMAS DE ESTUDIO DE LA CULTURA POLÍTICA}

Las siguientes páginas apuntan aunque sea brevemente, algunas de las problemáticas teóricas y empíricas más influyentes en el estudio reciente de la cultura política. Nos referimos a cinco ejes analíticos: los nuevos perfiles de la cultura política, valores y cultura política, apoyo político, desafección política y sentimientos antipartidistas.

\subsection{LOS NUEVOS PERFILES DE LA CP}

Una de las preocupaciones que más ha llamado la atención de los estudiosos de esta etapa de renacimiento, es la referida a las nuevas pautas de la cultura política de finales del siglo veinte. La razón no es accidental; según la nueva generación, los cambios estructurales $y$ culturales que afectaron a las sociedades industriales avanzadas en la segunda mitad del siglo veinte, impactaron los contenidos centrales de la cultura política ${ }^{11}$. De ese modo, desde los años noventa, los estudiosos construyeron nuevos acercamientos al análisis de esta temática.

Una de las aportaciones más sistemáticas es la de Ma. De la Luz Morán \& Jorge Benedicto (1995). En un análisis de la cultura política de los españoles en la transición y la consolidación democrática, los autores formularon un esquema dimensional de la cultura politica articulado por cuatro dimensiones analíticas: el individuo-ciudadano como actor, la vinculación ciudadano-política, las imágenes ciudadanas del sistema político y los resultados de la acción institucional. La primera dimensión refiere a las creencias que configuran el marco de referencia a partir del cual el individuo plantea su relación con el mundo de las significaciones colectivas y se construye como actor político real o potencial; la segunda -o vinculación ciudadano y política - articula las relaciones que el ciudadano mantiene con la esfera política en general y con el sistema político en particular; la tercera -o imágenes del sistema político- aborda las bases de la legitimidad del sistema político democrático; por último, la cuarta dimensión - resultados de la acción institucional- alude a la evaluación ciudadana de la acción institucional, fundamentalmente la que llevan a cabo los gobiernos. Estas cuatro dimensiones fueron desagregadas en doce componentes (valores sociales, creencias políticas básicas, socialización política, implicación política personal, política y medios de comunicación, asociacionismo, participación política, sistema democrático, actores e instituciones políticas, labor gubernamental y Estado y bienestar social); $y$ estos componentes fueron construidos con un sinnúmero de variables.

Otras contribuciones importantes son las de van den Broek \& Heunks (1994), Ester, Halman \& Rukavishnikov (1997), Inglehart (1991 y 2006), Nevitte (1996) $)^{12}$ y Pollack,

11 M. Kaase \& K. Newton. Beliefs in Government, cap. 3. New York: Oxford University Press, 1998.

12

Van den Broek \& Heunks (1994) centran su atención en los nuevos patrones de la cultura política en 15 países occidentales (13 europeos, Canadá y los Estados Unidos) en dos momentos: 1981 
Jacobs, Muller \& Pickel (2003). La estrategia de los dos primeros autores, Andries van den Broek $\&$ Felix Heunks, plantea dos ejes analíticos: las orientaciones y la participación políticas. El primer eje articula cuatro variables: las orientaciones derecha-izquierda, el individualismo económico cultural, los valores posmaterialistas y un conjunto de actitudes políticas (confianza institucional, tolerancia e interés político); el segundo es construido con base en tres tipos de participación: la convencional, la no convencional y la desobediencia. Ronald Inglehart (1991) subrayó la importancia de cinco variables: satisfacción vital o bienestar subjetivo, confianza interpersonal, satisfacción política; discusión política y apoyo al orden social; en un estudio posterior, Inglehart \& Christian Weltzel (2006) apuntaron dos ejes: hay una serie de valores cívicos centrados en la libertad y la autoexpresión que son más importantes para la democracia que el apoyo abierto a las instituciones democráticas. Por su parte, Neil Nevitte analizó los cambios de la cultura política con base en cuatro variables: el interés político, la confian$\mathrm{za}$ en las instituciones gubernamentales y no gubernamentales, el sentimiento de comunidad o cosmopolitanismo político y la participación política.

\subsection{VALORES Y CULTURA POLÍTICA}

Un influyente estudioso del cambio cultural en el último cuarto del siglo veinte es, sin ninguna duda, Ronald Inglehart (1991, 2000 y 2004, 2006); según este autor, el cambio cultural tiene dos ejes: los valores posmaterialistas $y$ la cultura política. El primero alude al paso de un tipo de prioridades valorativas (las materialistas que enfatizan en la seguridad económica) a otro (las posmaterialistas que enfatizan en la autoexpresión, el sentimiento de pertenencia a la comunidad y la calidad de vida). Este giro

y 1990; Ester et ál (1997) comparan la cultura política rusa con la de 20 países europeos en varios momentos: 1983, 1988, 1990 y 1994; y Nevitte (1996) estudia el caso canadiense en dos momentos: 1981 y 1990 . valorativo, denominado como el surgimiento de los valores posmaterialistas (1991: 59) o el cambio intergeneracional de valores materialistas por otros posmaterialistas (p. 315), ha tenido un impacto de largo alcance es decir, ha afectado las motivaciones que se tienen para trabajar, las actitudes frente al ecologismo y la energía nuclear, el papel que juega la religión, las actitudes que se adoptan ante el rol de las mujeres, la homosexualidad, el divorcio, el aborto y muchos otros temas". Igualmente, este giro valorativo está contribuyendo a remodelar la base social del conflicto político y los alineamientos políticos e ideológicos, desplazar el centro de atención hacia nuevos temas políticos, debilitar las formas tradicionales de participación e incrementar el potencial de la participación política no convencional, impulsar la aparición de nuevos movimientos sociales al mismo tiempo que ha estimulado cambios importantes en las orientaciones $y$ la cultura política.

Otros estudiosos han destacado la importancia de diversos componentes de los valores y actitudes políticas en la experiencia de los países post socialistas, los europeos occidentales y los latinoamericanos. Kristin Broderick (2000) examinó los efectos económicos (operacionalizados en términos de reforma económica, condiciones económicas y situación financiera personal) sobre el apoyo popular a la democracia en cuatro países de la Europa central y oriental que transitan a la consolidación democrática: República Checa, Eslovenia, Lituania $y$ Rusia. Francisco Garmendia \& Xabier Barandiaran Irastorza (2002) examinaron los valores políticos más sobresalientes —como son por ejemplo, la identidad y la autoidentificación, la valoración del proceso democrático, la tolerancia/intolerancia, la libertad/igualdad, y las formas de acción política- de la población vasca de Alava, Bizkaia, Gipuzkoa y Navarra. Matthew Kenney (2003) abordó las relaciones entre valores, actitudes liberales (por ej., libertad, autoridad, derechos individuales y compromiso democrático) y estabilidad democrática en ocho países: cuatro democracias establecidas (Alemania, Estados Unidos, Noruega y Suecia) y cuatro nuevas democracias (Argentina, Brasil, Chile y México). 


\subsection{APOYO POLÍTICO}

Formulado originalmente por David Easton (1965 y 1975), el apoyo político es definido como los "sentimientos de confianza o afecto, o sus opuestos" que los ciudadanos dirigen a los objetos políticos (Abramson, 1987: 170) o el conjunto de orientaciones afectivas $y$ evaluativas hacia los objetos y procesos políticos (Fuchs, 1993; Kornberg \& Clark, 1992). Easton distinguió tres objetos (comunidad política, régimen $y$ autoridades) $y$ dos tipos de apoyo (apoyo difuso y apoyo concreto) ${ }^{13}$. En los años ochentas, esta propuesta fue refinada y ampliada por estudiosos norteamericanos - como son Russell Dalton y Pippa Norris- canadienses -Neil Nevitte-y europeos — como los alemanes Dieter Fuchs y Hans Dieter Klingemann, el austriaco Christian Haerpfer, los británicos Geoffrey Evans y Richard Rose, los españoles José Ramón Montero y Mariano Torcal, el italiano Leonardo Morlino, el noruego Ola Listhaug, $y$ el sueco Soren Holmberg. En esta etapa, el apoyo político aparece como una constelación actitudinal (Klingemann, 1999) compuesta por cinco objetos o niveles analíticos: a) la comunidad política o apego ciudadano a la nación y compromiso o identificación con el orden social $y$ político; b) los principios del régimen político o adhesión ciudadana al sistema y los valores democráticos; c) el rendimiento del régimen o satisfacción ciudadana con el funcionamiento del sistema democrático; d) la evaluación institucional mide el funcionamiento y la confianza ciudadana en las instituciones políticas y e) la evaluación de los actores y autoridades políticas mide la actuación confianza ciudadana en los diferentes actores políticos.

En el plano empírico existe una vasta bibliografía. Para citar unos pocos de los trabajos más representativos, Russell Dalton (1999) elaboró una visión comparativa de las tendencias del apoyo político en cuatro democracias industrial avanzadas: Francia, Gran Bretaña,

El estudio de Kornberg \& Clark (1992) es quizás el examen más detallado del apoyo político en una experiencia concreta - la democracia canadiense - según la tradición tripartita establecida por Easton.
República Federal de Alemania y Estados Unidos. Con base en los datos recogidos por varias encuestas internacionales, el autor analizó la confianza en las autoridades políticas y las instituciones políticas - enfatizando la tendencia declinante de la identificación partidista-, evaluó el rendimiento del régimen o el funcionamiento del proceso democrático, el apoyo a los principios democráticos y a la comunidad política. Allan Kornberg \& Harold Clark (1992) exploraron las variaciones del apoyo a la comunidad, el régimen y las autoridades políticas en Canadá en los quince años comprendidos entre 1974 y 1988; Hans-Dieter Klingemann (1999) hizo un mapeo de los patrones y formas de apoyo ciudadano en poco más de sesenta sistemas políticos. Con base en los datos de la EMV 1990 y 1995, el autor revisó tres variables centrales: la comunidad política, la democracia como forma ideal de gobierno y la evaluación del funcionamiento del régimen; Pamela Waldron-Moore (1999) exploró el apoyo a las instituciones democráticas, la satisfacción con el gobierno democrático y los vínculos de ésta con el apoyo político en seis países ex socialistas: Hungría, Lituania, Polonia, Rusia, Ucrania y la República Checa; José Ramón Montero y Leonardo Morlino (1993) examinaron la adhesión ciudadana a la democracia y la satisfacción con el funcionamiento de la democracia, en cuatro países del sur de Europa: Portugal, España, Italia y Grecia; Fuchs (1993 y 1998) midió la satisfacción con el funcionamiento de la democracia en la República Federal de Alemania y en trece países europeos respectivamente; y Ola Listaug (1998) examinó los patrones de confianza ciudadana en las instituciones -gubernamentales $y$ no gubernamentales-y los políticos - funcionarios gubernamentales y líderes de los partidos políticos. En una obra reciente, Dalton (2006) hizo una revisión de la bibliografía referida a los cambios ocurridos en la confianza ciudadana en los políticos, las instituciones políticas y el proceso democrático en los países industrial avanzados.

\subsection{DESAFECCIÓN POLÍTICA}

A inicios del siglo veintiuno, las nuevas aportaciones teóricas y empíricas del análisis 
europeo de la cultura política, han tenido como resultado el desarrollo de un nuevo campo analítico: la desafección política ${ }^{14}$. Una definición mínima refiere al conjunto de actitudes $y$ orientaciones que implican un alejamiento o desapego ciudadano con respecto del sistema político (Torcal, 2000). En tal perspectiva, la desafección política puede ser definida como el sentimiento subjetivo de ineficacia política, desinterés político y falta de confianza ciudadana.

Esta definición requiere de varias precisiones. Primero, los estudios más recientes y sobre todo, los análisis derivados de la Encuesta Social Europea han planteado la existencia de dos tipos de desafección: el desapego político (Martín, 2005) y la desafección institucional (Pena \& Torcal, 2005). El primer tipo se descompone en tres variables: el interés que los ciudadanos tienen por la política o, dicho de otro modo, el nivel de curiosidad que la política suscita entre los ciudadanos, la percepción que el ciudadano tiene de sí mismo como actor o como parte del proceso político (o eficacia interna) y la predisposición hacia la participación política (Martín, 2005). El segundo tipo o desafección institucional "hace referencia a los sentimientos de desconfianza hacia los representantes y las instituciones políticas" (Pena \& Torcal, 2005: 83) y se desagrega igualmente en tres variables: confianza institucional, satisfacción con el sistema democrático y eficacia externa. La primera variable alude a la confianza que

Aunque los antecedentes analíticos se encuentran en la obra clásica de Giuseppe di Palma, Apathy and Participation: mass politics in western societies (Free Press, 1970), el análisis contemporáneo inicia con la tesis doctoral de Mariano Torcal Political disaffection in New Democracies: Spain in comparative perspectiva, The Ohio State University, 2002. Entre las contribuciones posteriores del mismo autor destacan "La desafección en las nuevas democracias del sur de Europa y Latinoamérica". Revista Instituciones y Desarrollo 8-9. 2001. M. Torcal, L. Morales \& Santiago PérezNievas (eds.). España: Sociedad y Politica en Perspectiva Comparada: un análisis de la primera ola de la Encuesta Social Europea. Valencia: Tirant lo Blanch, 2005; y M. Torcal \& J.R. Montero (eds.). Political Disaffection in Contemporary Democracies: Social Capital, Institutions and Politics. Londres: Routledge, 2006. los ciudadanos depositan en las instituciones gubernamentales (por ej., el parlamento) y no gubernamentales (por ej., la iglesia) así como en los actores políticos (los funcionarios y los políticos) y no políticos; la segunda refiere a las opiniones y evaluaciones sobre el funcionamiento de la democracia; $y$ la tercera alude a la percepción ciudadana que se tiene de la receptividad de los funcionarios públicos y políticos a los problemas y demandas de aquellos. Segunda precisión: los dos tipos de desafección revelan un "distanciamiento preocupante" de la ciudadanía respecto de las instituciones y la clase política (Pena \& Torcal, 1995); sin embargo, estos sentimientos subjetivos no conducen ni concluyen con el cuestionamiento de la legitimidad del régimen político. En otras palabras, la desafección política "es independiente del grado de apoyo al régimen y no constituye por tanto, un indicador del mismo" (Torcal, 2001) ${ }^{15}$. Por último, tercera precisión: entendida la desafección como un síndrome, es posible situar sus síntomas en un continuun que partiendo de un polo positivo de ciudadanos completamente integrados y con fuertes sentimientos de cercanía a su sistema político, y pasando por una serie de puntos intermedios caracterizados por un cierto desapego respecto a elementos significativos del régimen, alcanzaría un polo negativo definido por una hostilidad completa hacia el sistema político y un consecuente alejamiento del mismo.

\subsection{SENTIMIENTOS ANTIPARTIDISTAS}

Una temática clásica, la referida a la relación ciudadano-partido, identificación partidista y participación electoral, está compartiendo su lugar con una nueva: las actitudes ciudadanas hacia los partidos o más específicamente, los sentimientos antipartidistas. De acuerdo con los

15 
estudiosos, a lo largo de las últimas dos décadas del siglo veinte, el apoyo ciudadano a las instituciones políticas a la par que las valoraciones o la imagen pública de los partidos políticos experimentó un rápido deterioro tanto en las viejas democracias occidentales como en las nuevas - por ejemplo, las latinoamericanas. Según una primera línea interpretativa, los sentimientos antipartidistas tienen raíces profundas en la experiencia histórica y la cultura política de una sociedad determinada; una segunda arguye que este sentimiento es un fenómeno general de largo plazo y forma parte del declive de la confianza en las instituciones representativas; $y$ una tercera apunta que estas orientaciones son respuestas transitorias de los ciudadanos a los acontecimientos políticos de los años noventa.

Pero ¿a qué refiere el antipartidismo? Según Poguntke \& Scarrow (1996: 320-325) los sentimientos antipartidistas aluden a aquellas orientaciones desfavorables - 0 negativashacia los partidos entre las elites intelectuales $y$ políticas y el público en general. A partir de esta definición mínima, la bibliografía destaca dos dimensiones o tipos: el "antipartidismo reactivo" y el "antipartidismo cultural" (Torcal, Montero \& Gunther, 2003). La primera dimensión o antipartidismo reactivo es la posición crítica adoptada por los ciudadanos como respuesta a su insatisfacción con las actividades de las elites de los partidos y los rendimientos de las instituciones; mientras tanto, el antipartidismo cultural está enraizado en las tradiciones históricas y en los valores centrales de la cultura política, independientemente de los cambios en el corto plazo de las condiciones políticas del país $y$, por lo tanto, relativamente estable a lo largo del tiempo en términos de su alcance e intensidad (p. 12-16).

La bibliografía disponible reporta numerosos indicadores. En un estudio sobre el antipartidismo en España, Portugal, Italia y Grecia (1985-1998), Torcal, Montero \& Gunther (2003: 16-23) midieron la importancia de seis indicadores: 1) los partidos se critican mucho entre sí, pero en realidad todos son iguales; 2) los partidos políticos solo sirven para dividir a la gente; 3 ) sin partidos no puede haber democracia; 4) los partidos son necesarios para defender los intereses de los distintos grupos y clases sociales; 5) Gracias a los partidos la gente puede participar en la vida política; $y$ 6) los partidos no sirven para nada.

\section{LA BIBLIOGRAFÍA}

Este inventario bibliográfico reune un total de sesenta y cuatro títulos; de estos, cuarenta $y$ tres son comentados, es decir, los comentarios refieren a un libro, un libro colectivo, un artículo en revista especializada o artículo en libro colectivo. La selección fue realizada con base en varios criterios. El primero refiere a la orientación teórica y metodológica de la bibliografía; en términos generales, este inventario recoge aquel tipo de análisis fundado en datos recolectados mediante el uso del cuestionario.

El segundo criterio apuntó a la inclusión de trabajos de naturaleza teórica, metodológica y empírica. Las obras de Samuel Barnes y Max Kaase sobre la participación en cinco democracias occidentales (1979, cap. 1) y de Ma. Luz Morán \& Jorge Benedicto sobre la cultura política de los españoles (1995, cap. 1) ilustran los esfuerzos de construcción teórica; la contribución reciente de Laura Morales sobre el asociacionismo político en las democracias occidentales (2006, cap. 1 y 2) y el de Pamela P. WaldronMoore (1999) sobre el apego democrático y la satisfacción con el gobierno democrático en seis países de la Europa central y oriental, muestran la articulación de la teoría y la metodología en la medición del problema bajo análisis. El inventario bibliográfico también incluye trabajos de revisión y sistematización teórica y metodológica: los artículos de Glenda Patrick (1983), Damarys Canache (2001), Oscar Gabriel \& Jan van Deth (1998), Richard Rose (2002), James Wright (1981) o los libros de Paul Abramson (1987) y Russell Dalton (2006) constituyen una evaluación de la bibliografía disponible en un determinado campo o problemática: el concepto de cultura política, el ítem "satisfacción con el funcionamiento de la democracia”, la medición del interés político, las mediciones del apego y la satisfacción democrática mediante encuestas, el concepto de desafección, alienación o descontento político, y el estudio de las actitudes políticas y el apoyo político. 
El tercer criterio buscó asegurar que este inventario permita reconstruir la vitalidad teórica, metodológica y empírica del renacimiento intelectual de los estudios sobre cultura política; en ese sentido, hemos tratado de asegurar que esta bibliografía nos permita conocer con algún detalle, las principales temáticas y orientaciones teóricas y metodológicas desarrolladas por la nueva generación de estudiosos. En este punto, cabe subrayar la presencia dominante de varias perspectivas: primero, la teoría de los valores o más particularmente, la de los valores posmaterialistas, propuesta y desarrollada por Inglehart (1991, 2000 y 2006); segundo, la propuesta de los apoyos democráticos derivada de las elaboraciones teóricas de Robert Dahl (Waldron-Moore, 1999); tercero, el análisis del apoyo político. Una primera versión de esta propuesta, la clásica, fue formulada por David Easton en los años sesenta y setenta $y$ aplicada magistralmente al análisis de la experiencia canadiense por Kornberg \& Clarke (1992); una segunda versión es la propuesta refinada $y$ ampliada que han desarrollado numerosos autores (Dalton, 2004; Klingemann \& Fuchs, 1998; Nevitte, 2002; Norris, 1999) y que hoy en día, domina teórica y metodológicamente, el campo de estudio ${ }^{16}$. Otras importantes contribuciones al análisis de la $\mathrm{CP}$ de fines del siglo veinte y principios del veintiuno son las explicaciones institucionales (Norris, 1999), las perspectivas del cambio social (Dalton, 2006; Mayer, 1993), el aprendizaje y reaprendizaje político (Mishler \& Rose, 2002; Rohrschneider, 1999), el reemplazo generacional (Mayer, 1993), los enfoques de la legitimación, el comunitario y del desarrollo humano (Inglehart \& Weltzel, 2006), la confianza política (J. Hibbing \& E. Theiss-Morse, 1995; Nye et ál., 1998), el cambio de valores (Dalton, 2006) y los valores políticos (Inglehart, 1991; Kenney, 2003; Miller, Reisinger \& Hesli, 1993; Pollack et ál, 2003), etc.

El último criterio refiere a los países. Este inventario no trata de la CP en América Latina; por lo mismo, no reporta ningún trabajo sobre el conjunto de la región o sobre algún país en

Esta perspectiva analítica ha generado una primera oleada de crítica teórica y metodológica; véanse los trabajos de Canache et ál (2001), Linde \& Ekman (2003) y Rose (2002). particular. Los estudios de caso refieren a los democracias industrial avanzadas, a los sociedades exsocialistas y algunos países asiáticos. Para citar unos pocos casos nacionales: en el primer grupo se trata de análisis referidos entre otros, a Alemania, Canadá, Dinamarca, España, Estados Unidos, Francia, Gran Bretaña, etc.; en el segundo grupo incluimos estudios referidos a países como son Estonia, Hungría, Lituania, Polonia, Rumania, Rusia, Ucrania, etc.; y en el tercer grupo destacan dos países: Corea y China. Una bibliografía sobre la cultura política en América Latina y México, cada vez más abundante, merece un reporte especial.

\section{BIBLIOGRAFÍA}

\section{P. Abramson. Las Actitudes Politicas} en Norteamérica. Bs. As. Grupo Editor Latinoamericano, 1987: 398. [edic. original: Political Attitudes in America: formation and change. W.H. Freeman \& Co., 1983].

Este libro hace una revisión de la bibliografía empírica referida a tres variables de la CP: identificación partidista, eficacia política y confianza política. La primera parte (caps. 1-4) introduce al estudio de las actitudes políticas $y$ bosqueja un panorama de los principales cambios ocurridos en las actitudes y conductas políticas de la población norteamericana en los años de posguerra. La revisión de los tres temas - erosión de la lealtad partidista (parte 2, caps. 5-7), debilitamiento del sentimiento de eficacia política (parte 3, caps. 8-10) y declinación de la confianza política (parte 4, caps. 11-13) - sigue la misma lógica: el primer capítulo explica el concepto y su medición; el segundo muestra cómo estas actitudes son aprendidas en la edad preadulta; $y$ el tercero examina el cambio actitudinal en la edad adulta. Las conclusiones (cap. 17) destacan los "efectos del reemplazo generacional sobre la distribución total de actitudes entre el electorado" (ps. 365-367), las brechas en el estudio de las actitudes políticas (ps. 367-370) y el futuro de estas "que dependerá mucho más de los acontecimientos sociales y políticos" (p. 375). 
02. Ch. Anderson. Blaming the Government: citizens and the economy in five european democracies. Londres. M.E. Sharpe, 1995, $232 \mathrm{p}$.

Este libro examina un tema poco explorado: el impacto de las condiciones macroeconómicas sobre las actitudes y conductas ciudadanas que expresan apoyo político (p. 31) al gobierno, los partidos gobernantes y las coaliciones políticas en cinco democracias europeas: Alemania, Dinamarca, Francia, Gran Bretaña y Holanda. El libro se compone de nueve capítulos: el primero ofrece un cuadro teórico de las relaciones entre resultados económicos, electorado y gobierno democrático; el segundo ilustra el comportamiento de las tendencias macroeconómicas de la posguerra (1950-1990) en los cinco países seleccionados; los dos siguientes exploran las estrategias analíticas y el quinto sistematiza los modelos de apoyo gubernamental en la Europa occidental y especifica las "hipótesis clásicas". Los tres capítulos siguientes constituyen el eje del análisis empírico: los casos alemán, danés y holandés son estudiados en el capítulo seis, el francés en el siete y el caso inglés en el ocho. El último capítulo presenta las conclusiones y discute las implicaciones del estudio para la investigación futura sobre la conexión entre condiciones macroeconómicas y apoyo a la política gubernamental.

03. S. Barnes \& M. Kaase (eds.). Political Action: mass participation in five western democracies. Beverly Hills. Sage, 1979, $607 \mathrm{p}$.

04. S. Barnes \& J. Simon (eds.). The Postcommunist Citizen. Budapest. Erasmus Foundation \& Institute for Political Science of the Hungarian Academy of Sciences, 1998, 272 p.

05. D. Berg-Schlosser \& R. Rytlewski (eds.). Political Culture in Germany. New York. St. Martin's Press, 1993, 370 p. (23L).

Esta obra colectiva e interdisciplinaria busca explicar los desarrollos de la CP alemana. El libro se compone de seis partes. El análisis inicia con la formación histórica de la CP: los legados del imperio (cap. 3), la identidad y el consenso en la República del Weimar (cap. 4), la relación cultura y política en el nazismo (cap. 5) y las continuidades y cambios en los primeros años de la segunda posguerra (cap. 6). La tercera explora las variaciones y tipos regionales de CP (caps. 7-8), y las relaciones con los movimientos sociales (cap. 9) y la extrema derecha (cap. 10). Las dos partes siguientes están dedicadas a la CP en las dos repúblicas alemanas, previas a la caída del Muro de Berlín; en el conjunto de trabajos destaca la propuesta clásica de Dieter Fuchs (cap. 16) sobre el ítem satisfacción con el funcionamiento de la democracia, "instrumento útil para la medición de una actitud generalizada hacia el proceso político" (p. 234). En la última parte del libro, Bettina Westle analiza los aspectos cambiantes de la identidad nacional después de la unificación (cap. 17). Con base en los datos de varias encuestas realizadas entre 1989 y 1990, la autora mide el apoyo difuso, el apoyo afectivo, el apoyo instrumental $y$ la satisfacción con la unificación, el orgullo nacional, el apoyo al sistema democrático; el análisis revela que los alemanes orientales han desarrollado lazos afectivos a la "nueva comunidad política" (p. 291). El último capítulo (cap. 20), escrito por los editores, plantea los nuevos problemas que emergen como resultado de la caída del Muro de Berlín y la unificación de las dos Alemanias.

06. K. Broderick. The Economy and Political Culture in New Democracies: an analysis of democratic support in Central and Eastern Europe. Aldershot-GB. Ashgate, 2000.

07. A. van den Broek \& F. Heunks. "Political culture: patterns of political orientations and behaviour". P. Ester, L. Halman \& R. de Moor (eds.). The Individualizing Society: value change in Europe and North America. Tilburg. Tilburg University Press, 1994: 67-96.

Los autores plantean dos ejes analíticos: las orientaciones y la participación políticas. El primero es delimitado a cuatro variables: las 
orientaciones derecha-izquierda, el individualismo económico cultural, los valores posmaterialistas y un conjunto de actitudes políticas (confianza institucional, tolerancia e interés político). El segundo eje es construido con base en tres tipos de participación: la convencional, la no convencional y la desobediencia. El análisis centra su atención en los nuevos patrones de la cultura política en 15 países occidentales (13 europeos, Canadá y los Estados Unidos) en dos momentos: 1981 y 1990. Los datos utilizados proceden del European Values Studies que realiza el European Values Systems Study Group desde fines de los años setenta.

08. D. Canache, J. Mondak \& M. Seligson. "Meaning and measurement in crossnational research on satisfaction with democracy". Public Opinion Quaterly 65 (4). 2001: 506-528.

Los autores examinan las propiedades analíticas de un ítem que mide la satisfacción con el funcionamiento de la democracia. Utilizado en diferentes encuestas internacionales (como la Encuesta Mundial de Valores, el Eurobarómetro, el Latinobarómetro) y analizado por influyentes estudiosos del tema (como son Russell Dalton, Dieter Fuchs, Ronald Inglehart, Pippa Norris, Richard Rose et ál., Doh Shin), este ítem no ha generado consenso acerca de qué mide. A partir de una revisión de la bibliografía empírica disponible, los autores identifican cinco significados del ítem, detectan sus ambigüedades conceptuales y metodológicas, $y$ analizan con base en tres encuestas realizadas en El Salvador, Rumanía y 17 países latinoamericanos, las correlaciones del ítem con tres indicadores: apoyo a las autoridades, apoyo al sistema y apoyo a la democracia como forma de gobierno.

09. R. Dalton. Citizen Politics: public opinion and political parties in advanced democracies. Chatham-New Jersey. Chatham House Publishers, 1996, 338 p.

Este libro es una obra referencial en el análisis comparado de "la opinión pública y el comportamiento político" (p. 3) en cuatro democracias industrial avanzadas: Alemania,
Estados Unidos, Francia y Gran Bretaña (pp. 47). El eje del análisis destaca las motivaciones, expectativas, actitudes y comportamientos del ciudadano promedio. El punto de partida subraya que las transformaciones socioeconómicas y políticas ocurridas desde los años cincuenta en los países avanzados, han generado un nuevo estilo de política ciudadana que se expresa en un mayor interés e información política, protestas y nuevos movimientos sociales, volatilidad electoral, escepticismo y desconfianza en las elites y las instituciones políticas. La exposición está estructurada en torno de cuatro problemáticas: la participación y la protesta (caps. 2-4), los valores y las orientaciones políticas (caps. 5-6), los partidos, las preferencias y los comportamientos electorales (caps. 7-11) y el impacto de las nuevas orientaciones $y$ actitudes sobre el proceso democrático (cap. 12). La exposición de las cuatro problemáticas subraya los desarrollos teóricos del campo de estudio, discute los problemas de construcción y medición de las variables y reinterpreta los datos que, en su conjunto, muestran la existencia de un nuevo perfil político del "ciudadano promedio" y sus efectos sobre el orden político tradicional.

10. R. Dalton. Political support in advanced industrial democracies. P. Norris. 1999: 57-77.

11. R. Dalton. Democractic ChallengesDemocratic Choices: the erosion of political support in advanced industrial democracies. New York. Oxford University Press, 2006, 230 p.

Las democracias industrial-avanzadas contemporáneas enfrentan una nueva amenaza que tiene sus orígenes en la erosión de la confianza y el apoyo ciudadano (cap. 1) a los políticos, los partidos y las instituciones políticas que se desarrolló, según los países, a lo largo del último cuarto del siglo veinte (p.191). El libro se compone de tres partes y nueve capítulos. La primera analiza los cambios producidos en la evaluación ciudadana de las autoridades políticas, el régimen, las normas y procedimientos del régimen político, el apoyo a la democracia y la comunidad política (cap. 
2). La segunda parte, "Las fuentes del cambio", examina los correlatos del apoyo político (cap. 3 ), el declive del apoyo político según grupos sociales y países (cap. 4), y las teorías disponibles, que son sometidas a prueba empírica (caps. 4, 5, 6 y 7). El examen empírico subraya las teorías del cambio, la del cambio de valores (cap. 5), la de las percepciones económicas (cap. 6) y la teoría de las preferencias políticas o policy preferences (cap. 7). La tercera parte, "Los efectos del cambio", dirige su atención a las consecuencias potenciales del cambio en las orientaciones políticas de los ciudadanos; más específicamente, examina el impacto de la erosión del apoyo político (cap. 8) o la presencia de un nuevo tipo de ciudadanos: los ciudadanos críticos o "demócratas insatisfechos" (p. 45); este último análisis destaca cinco dimensiones: la evaluativa, la afectiva, la cognitiva, la participativa y la institucional.

12. P. del Castillo \& I. Crespo (eds.). Cultura Política. Valencia. Tirant lo Blanch, 1997, $278 \mathrm{p}$.

Este libro recoge ocho trabajos que giran alrededor del papel que la cultura política (CP) desempeña en la emergencia y consolidación de los regímenes democráticos. Según los editores, el libro proporciona instrumentos teóricos $y$ empíricos que contribuirán a despejar algunos de los dilemas que enfrentan los estudiosos de la CP (p. 11). En tal dirección, la obra se organiza con base en tres líneas argumentales: la primera, compuesta por dos capítulos teóricos $y$ metodológicos, revisa exhaustivamente la categoría conceptual, los enfoques o paradigmas teóricos y los enfoques críticos a la obra clásica de Almond \& Verba. La segunda parte se compone de cuatro capítulos que dirigen su atención a las relaciones CP y estabilidad democrática: "Elementos de cultura política en la Unión Europea" escrito por los editores, "Actitudes políticas en Europa del este" de Carmen González, "Elites parlamentarias y CP en América Latina” de Antonia Martínez y "Valores sociales de mercado en la cultura política de la Liga Norte" de Cesáreo Aguilera del Prat. Por último, los dos capítulos que componen la tercera parte refieren al papel de los ciu- dadanos y las élites en la construcción de una cultura política democrática en la transición y consolidación de la democracia española. Ma. de la Luz Morán aborda el papel de las elites mientras Jorge Benedicto examina las bases culturales de la ciudadanía democrática.

13. M. Delli Carpini \& S. Keeter. What Americans Know about Politics and Why it Matter. New Haven. Yale University Press, 1989, 397 p.

Este libro examina sistemática y detalladamente, el conocimiento político del ciudadano estadounidense. Definido como la información factual de la política (cap. 1 y apéndice 2) y lo que el ciudadano "necesita saber qué es $y$ hace el gobierno" (p. 63), el conocimiento político es medido en cinco campos: 1) instituciones y procesos políticos, 2) personajes, grupos y partidos, 3) política nacional, 4) política internacional, y 5) geografía e historia social y política (cap. 2). El análisis empírico cubre un período de poco más de medio siglo (1940-1994) y está basado en las encuestas realizadas por diversas instituciones, estudiosos y los mismos autores (apéndice 3). El capítulo tres: "Estabilidad y cambio en el conocimiento político" presenta una primera visión comparada y muestra que el nivel de conocimiento es muy similar al de hace medio siglo; el capítulo cuatro: "Quién está informado" examina los patrones y distribución del conocimiento entre los "grupos demográficos" (p. 161) definidos según sexo, raza, ingresos, etc. Los dos siguientes capítulos pasan de la descripción al análisis: el quinto propone un modelo explicativo que subraya la influencia de numerosos factores como la motivación cívica, la educación formal, las diferencias de los grupos, etc. El último capítulo discute las consecuencias del conocimiento $y$ la ignorancia política sobre el apoyo a los valores democráticos y la participación política.

14. L. Diamond (ed.). Political Culture and Democracy in Developing Countries. Boulder-Colorado. Lynne Rienner Pubs., 1994, 262 p.

Según el editor, esta obra busca llenar algunas lagunas $y$ brechas que presenta el estudio de 
la CP en sociedades "no democráticas" o en transición a la democracia (p. 15). El libro analiza la experiencia en cuatro regiones (Africa, Asia, Europa central y oriental y América Latina) y países (los del centro y sur africano, Costa Rica, seis países del centro de Europa, India, México y Nicaragua, Taiwan y Turquía). Los ejes analíticos subrayan las fuentes de la $\mathrm{CP}$, sus características más importantes y sus efectos en el corto y largo plazo, sobre la democracia. Al nivel de los análisis regionales, Naomi Chazan discute las fuentes, las dimensiones elitistas y populares así como la dinámica de la CP africana; $y$ Christine Sadowski centra su atención en "las barreras" que limitaron el desarrollo de una cultura política democrática en los regímenes socialistas. Al nivel de los casos nacionales, Ambrose King estudia el papel del confucionismo en el desarrollo democrático de Taiwan; Richard Sisson hace una revisión histórica de la interacción de las $\mathrm{CP}$ de las elites y las masas en el mantenimiento de la democracia hindú; $y$ Ergun Ozbudun centra su atención en los valores y actitudes políticas de las elites estatales turcas. John Booth \& Mitchell Seligson hacen un análisis comparado de dos componentes de la CP democrática en Costa Rica, México y Nicaragua: el apoyo a los derechos de participación ciudadana y el derecho a la disidencia o sentimientos de tolerancia política.

15. J. Díez Nicolás \& R. Inglehart (eds.). Tendencias Mundiales de Cambios en los Valores Sociales y Politicos. Madrid. Fundesco, 1994, $770 \mathrm{p}$.

Este libro reúne 36 trabajos que analizan diferentes dimensiones político-culturales recogidas por la Encuesta Mundial de Valores 1990 realizada en 43 países de los cinco continentes, que concentran a más del $70 \%$ de la población mundial. El objetivo de la obra es doble: verificar la existencia de una pauta de cambio más o menos común a todas las sociedades — con los ritmos y tiempos correspondientes a sus diferentes niveles de desarrollo económico-y sistematizar "las semejanzas y diferencias en las pautas de cambio en los valores sociales y políticos que se observan en las sociedades actuales". El libro se compone de ocho partes; tres de ellas y catorce capítulos refieren a la problemática de la cultura política: "la democratización en una perspectiva global" (parte 3), "ciudadanía y democracia" (parte 4) y "el cambio ideológico en el mundo ex-socialista" (parte 5). Estudiosos reconocidos como Elena Bashkirova, Juan Díez Medrano, Hans-Dieter Klingemann, Neil Nevitte, analizan las actitudes políticas, los valores democráticos, los valores posmaterialistas, la tolerancia, la participación política, y el continuun ideológico izquierda-derecha, en países como son Corea del Sur, los Estados Bálticos -Estonia, Letonia y Lituania-, España, Francia, Gran Bretaña, Polonia, Rusia, Sudáfrica, Suiza y Taiwan.

16. M. Dogan. "Erosion of confidence in advanced democracies". Studies in Comparative International Development 32 (3). 1997: 3-29.

17. P. Ester, L. Halman \& V. Rukavishnikov. From Cold War to Cold Peace? A comparative empirical study of russian and western political cultures. TilburgHolanda: Tilburg University Press, 1997.

El interés primario de este libro está centrado en el análisis de las consecuencias políticas del golpe de estado que se produjo en la Unión Soviética y la emergencia de una nueva cultura política en la sociedad rusa (p. 1). El enfoque subraya el análisis comparado de las similitudes $y$ diferencias de la cultura política - es decir, las orientaciones, creencias, actitudes y conductas políticas de los ciudadanos-en Rusia y los países occidentales - definidos como las sociedades de Europa central y occidental, Estados Unidos y Canadá. Los datos primarios proceden de las encuestas recogidas por el European Study Values (EvS) y el Instituto de Investigación Sociopolítica de la Academia Rusa de Ciencias. El libro destaca cuatro ejes analíticos de la CP rusa - el "síndrome" de la CP: satisfacción con la vida, confianza política y confianza interpersonal (cap. 3), valores materialistas-posmaterialistas (cap. 4), posición ideológica, preferencias partidistas y participación electoral (cap. 5) e identidad nacional (cap. 6)$y$ dos comparaciones: la CP (cap. 3) y la identidad nacional (cap. 6) en Rusia y el occidente. 
18. D. Fuchs. Trends of political support. D. Berg-Schlooser \& R. Rytlewski. 1993: 232-268.

Este capítulo es un trabajo referencial en el estudio del apoyo político. Con base en los datos del Eurobarómetro, el autor construye el ítem satisfacción con el funcionamiento de la democracia, "instrumento útil para la medición de una actitud generalizada hacia el proceso político" (p. 234). A partir de una descripción longitudinal del comportamiento del ítem (1977-1991), el autor analiza las tendencias de la dimensión satisfacción con la democracia en el contexto del cambio intergeneracional de valores. La discusión subraya que la tendencia hacia un declive constante en la satisfacción ciudadana con el funcionamiento de la democracia no puede ser confirmada (p. 264).

19. D. Fuchs, G. Guidorossi \& P. Svenson. Support for the democratic system. H.D. Klingemann \& D. Fuchs. 1998: 323-353.

20. O. Gabriel. Cambio Social y Cultura Política: el caso de la República Federal de Alemania. Barcelona. Gedisa editorial, 1990, $199 \mathrm{p}$.

De acuerdo al autor, "parece oportuno examinar críticamente las concepciones acerca de las actitudes de los ciudadanos (germano) federales con respecto a la política y la democracia" (p. 10). En el plano teórico, dos categorías orientan este análisis: cultura política $y$ apoyo político. Los cuatro capítulos centran su atención en las actitudes ciudadanas frente a la democracia, el gobierno y los partidos políticos. El primer capítulo da respuesta a una interrogante: ¿cómo influye en una democracia competitiva un cambio de gobierno en la lealtad de los grupos sociales al sistema político? El interés principal se centra en las actitudes de los simpatizantes de los partidos políticos con respecto al gobierno y al sistema político en el período anterior y posterior al cambio de gobierno (p. 47). El segundo, "Satisfacción con la democracia y actitudes democráticas" indaga la aprobación ciudadana de los principios democráticos y el sistema político; según el autor, los datos disponibles no permiten inferir una crisis de aceptación o de legitimidad en el sistema político" (p. 115). El tercero dirige su atención en dos cuestiones: la confianza en el gobierno y la conciencia de efectividad que se forma "en el transcurso de largos procesos de desarrollo histórico y en parte, están acuñadas por cambios a corto plazo en el sistema político o en su mundo circundante" (p. 133). El último capítulo refiere a la identificación partidista que constituye uno de los conceptos más importantes en la investigación empírica de los partidos (p. 166).

21. B. Hayes \& C.S. Bean. "Political efficacy: a comparative study of the United States, West Germany, Great Britain and Australia”. European Journal of Political Research 3. 1993: 261-280.

En la investigación clásica y la más reciente, la eficacia política ha sido conceptualizada y operacionalizada de muy diversas maneras. Con base en los datos del International Social Survey Programme 1985-1986, referidos a Alemania Occidental, Australia, Estados Unidos y Gran Bretaña, los autores revisan una batería de siete ítems que miden los sentimientos de eficacia política, clarifica sus dimensiones - eficacia interna $y$ eficacia externa- e investigan las relaciones con los factores sociodemográficos. Los datos sugieren que la eficacia interna $y$ externa son dimensiones actitudinales distintas y cada una está relacionada con ciertas características sociodemográficas.

22. A. Heath, S. Fisher \& S. Smith. "The globalization of public opinion research". Annual Review of Political Science 8. 2005: 297-333.

23. J. Hibbing \& E. Theiss-Morse. Congress as Public Enemy: public attitudes toward American political institutions. New York. Cambridge University Press, 1995, $186 \mathrm{p}$.

24. R. Hofferbert \& Ch. Anderson (eds.). "The Dynamics of Democratic Satisfaction". Número especial de International Political Science Review 22 (4). 2001. 
Este número monográfico de la International Political Science Review (2001) está dedicado a un subcampo de la CP: la evaluación y satisfacción (o insatisfacción) ciudadana con los sistemas políticos y gobiernos en un grupo de democracias nuevas y consolidadas. Los editores, Richard Hofferbert \& Christopher Anderson, reunieron a trece estudiosos de los valores y actitudes políticas (p. 299) que aportaron seis capítulos. En el primer capítulo, William Mishler \& Richard Rose describen y explican las variaciones en el apoyo político a 38 democracias incompletas y consolidadas; Anderson \& Yuliya Tverdova comparan las actitudes políticas de dos grupos - las mayorías o "ganadores" y las minorías o "perdedores"- y examinan sus evaluaciones al gobierno y las instituciones políticas en doce democracias nuevas y establecidas. Los dos capítulos siguientes refieren a la experiencia alemana. Steven Frinkel, Stan Humphries \& Karl-Dieter Opp exploran los cambios producidos en la relación valores socialistas y apoyo democrático en la ciudad de Leipzig (ex Alemania oriental); y Hofferbert \& Hans-Dieter Klingemann trazan las "intenciones" de comportamiento de tres grupos - los demócratas satisfechos, los demócratas insatisfechos y los no demócratas - en la democracia alemana "post-muro". Vicki Hesli \& Elena Bashkirova evalúan la influencia de las condiciones económicas en la evaluación ciudadana del presidente ruso Boris Yeltsin en distintos puntos del ciclo 1991-1999. Por último, Jack Dennis \& Diana Owen, estudian la satisfacción -insatisfacción ciudadana con los partidos políticos, el régimen político y los procesos democráticos en los Estados Unidos.

25. R. Inglehart. El cambio cultural en las sociedades industrial avanzadas. Madrid. Siglo XXI-Centro de Investigaciones Sociológicas, 1991, 539 p.

Este libro es una propuesta teórica y un análisis empírico del giro intergeneracional de valores materialistas a otros posmaterialistas en las sociedades industrial avanzadas y su impacto en las esferas social, cultural y política. La información procede de varias bases: las encuestas del Eurobarómetro recogidas entre
1970-1986, la Encuesta Mundial de Valores 1981-1982 aplicada en 24 países y el estudio panel llevado a cabo en Alemania, los Países Bajos y los Estados Unidos entre 1974 y 1981. El libro se compone de trece capítulos. El capítulo dos es un análisis teórico, metodológico y empírico de los valores posmaterialistas, eje de la propuesta teórica de Inglehart. Cinco capítulos están dedicados a los efectos políticos de los valores posmaterialistas: la polarización política -0 el tránsito de la base clasista a la base valorativa de los conflictos políticos (cap. 8)—; la ideología política - 0 el declive de la dimensión izquierdaderecha y el debilitamiento de las tradicionales identificaciones partidistas (cap. 9) —; el ascenso de la participación de masas —o el paso de "la política dirigida por élites a la política de élites dirigidas" (cap. 10)_; la emergencia de los nuevos movimientos sociales (cap. 11) y la cultura política (cap. 1). De acuerdo al autor, el bienestar subjetivo, la satisfacción política, la confianza interpersonal, las altas tasas de discusión política y el apoyo al orden social constituyen los ejes de la nueva CP asociada a la viabilidad de las instituciones democráticas (p. 32).

\section{R. Inglehart. Modernización y Postmo-} dernización: el cambio cultural, económico y político en 43 sociedades. Madrid. Siglo XXI-Centro de Investigaciones Sociológicas, 2000, 573 p.

Este libro se basa en los datos de la Encuesta Mundial de Valores 1990. La hipótesis central establece que los cambios en los sistemas de creencias y las nuevas prioridades valorativas entre las cohortes más jóvenes de la población, tienen consecuencias económicas, sociales, culturales y políticas. El libro se compone de once capítulos; en el campo de la cultura política, tres capítulos ofrecen nuevos datos e interpretaciones. El capítulo seis reporta que los nuevos "hallazgos sugieren que el papel de la cultura política en la democracia es mucho más importante de lo que indica la literatura de las últimas dos décadas. Aunque no parece ser la causa inmediata de la transición hacia la democracia, la cultura política es un factor central en la supervivencia de la democracia" (p. 284). El octavo subraya los vínculos 
entre valores posmaterialistas y cambios en las divisiones políticas que transitan del conflicto de clases a "cuestiones culturales y la preocupación por asuntos concernientes a la calidad de vida" (p. 314). El capítulo décimo, "La erosión de la autoridad institucional y la aparición de la intervención ciudadana en la política", muestra que "las instituciones consolidadas que han moldeado la sociedad industrial durante generaciones parecen estar perdiendo sobre el ciudadano medio. Disminuye la confianza no sólo en las instituciones públicas clave [...] sino también en los partidos políticos, las iglesias, los sistemas educativos y la prensa. Incluso descubrimos que se ha debilitado el sentimiento de apego a la institución occidental más básica, el estado nacional" (p. 425).

27. Inglehart, M. Basánez; J. Díez-Medrano; L. Halman \& R. Luijkx (eds.). Human Beliefs and Values: a cross-cultural sourcebook based on the 1999-2002 value surveys. México. Siglo XXI, 2004, 498 p.

Esta obra no es un análisis de la Encuesta Mundial de Valores (EMV) 2000 sino la presentación de los datos primarios sobre valores $y$ actitudes ciudadanas, recogidos por la EMV 2000. La infomación refiere a 81 sociedades nacionales que representan el $85 \%$ de la población mundial y cubren a países con los más diferentes niveles de riqueza y pobreza, desde regímenes políticos autoritarios hasta democracias consolidadas, a sociedades con los más diversos credos y prácticas religiosas, $y$ culturas que enfatizan desde "el conformismo hasta la emancipación humana y la autoexpresión" (p. 1). La primera parte del libro (pp. 1-20) presenta el proyecto, la segunda (p. 21-384) presenta las tablas de la EMV, y la tercera reporta cinco anexos técnico-metodológicos. Las tablas de la segunda parte cubren siete temáticas: percepciones de la vida, cuestiones ambientales, trabajo, familia, política y sociedad, religión y moral e identidad nacional; refieren a una pregunta del cuestionario con una de las respuestas $u$ opciones; $y$ están organizadas en siete columnas: país, porcentaje de la respuesta u opción en la Encuesta 1990 y 2000, género, grupos de edad, nivel educativo, nivel de ingreso $y$ valores (materialistas, mixtos y posmaterialistas). La sección E: Política y Sociedad reporta poco más de cien tablas que cubren un número importante de variables constitutivas de la CP (por ej., interés e información política, actitudes frente al cambio social, posición político-ideológica, participación política, potencial participativo, confianza institucional, evaluación de los sistemas políticos, satisfacción con la democracia, etc.). Finalmente, el libro se acompaña de un CD con la base de datos.

28. R. Inglehart \& Weizel. Modernización, Cambio Cultural y Democracia: la secuencia del desarrollo humano. Madrid. Centro de Investigaciones Sociológicas, 2006, 448 p.

De acuerdo con los autores, este obra presenta una versión revisada de la teoría de la modernización que integra el desarrollo socioeconómico, el cambio cultural y la democratización en el contexto del desarrollo humano. El libro se compone de dos partes: la primera centra su atención en las fuerzas que moldean el cambio de valores y la segunda destaca las consecuencias del cambio de valores. La primera parte (capítulos 1 al 6) enfatiza en el cambio de valores y la persistencia de las tradiciones culturales, el cambio intergeneracional de valores y los valores de la autoexpresión que constituyen "las orientaciones valorativas más importantes para el desarrollo humano y el surgimiento de la democracia” (p. 11). La segunda parte (capítulos 7 al 13) se ocupa de la influencia societal en las cambiantes orientaciones. Desde la perspectiva de la cultura política, son importantes cuatro capítulos: el vínculo causal entre valores democráticos e instituciones democráticas, analizado en el teórico (cap. 7) y el empírico (cap. 8); las relaciones valores en el nivel individual, $y$ la democracia en el nivel del sistema (cap. 10) y los componentes de la cultura cívica prodemocrática (cap. 11). Este capítulo examina las variables más importantes de la cultura cívica y busca "determinar qué orientaciones de masas influyen más en la democracia" (p. 328). Los resultados muestran que los valores de la autoexpresión (cap. 6) son cruciales para la democracia. 
29. M. Kaase \& K. Newton (eds.). Beliefs in Government. New York, Oxford University Press: 1998. (ver Inglheart 2001: 429).

Este libro es el quinto y último volumen de la serie Beliefs in Government, programa de investigación impulsado por la European Science Foundation en el conjunto de la Europa occidental: desde Portugal hasta Finlandia y desde Irlanda hasta Grecia. Esta obra presenta una síntesis del proyecto y reporta los hallazgos más importantes de los 64 capítulos que conforman los primeros cuatro volúmenes de la serie. El primer capítulo plantea los ejes del proyecto comparativo; el segundo revisa las teorías de la crisis y el cambio con el propósito de generar hipótesis. La primera parte refiere a las teorías de las contradicciones, las crisis y las catástrofes: la sociedad de masas (Kornhauser), la crisis de legitimidad (O'Connor, Offe y Habermans), la ingobernabilidad (Huntington), los nuevos movimientos sociales (Touraine, Melucci) y la política posmoderna (Lash \& Urry); la segunda refiere a las teorías del cambio y la transformación política: el fin de las ideologías (Bell, Lipset), el fin de la historia (Fukuyama), posmaterialismo (Inglehart). Los tres capítulos siguientes reportan la evidencia empírica relevante a las ocho teorías. La información y los datos se organizan en torno a tres ejes temáticos: las actitudes y conductas políticas (cap. 3), las opiniones y juicios ciudadanos acerca del papel y la acción gubernamental (cap. 4) y las actitudes de apoyo y oposición a un "gobierno internacional" (p. 98) en la Europa occidental. Los dos últimos capítulos discuten algunos elementos centrales de la relación Estado-ciudadano (cap. 6) e identifican tendencias potenciales para el futuro europeo.

30. M. Kenney. A Theoretical Examination of Political Values and Attitudes in New and Old Democracies. Gales-GB: Edwin Mellen Press, 2003.

31. H.D. Klingemann. Democracy and Political Culture in Eastern Europe. Londres: Routledge, 2006.
32. H.D. Klingemann. Mapping political support in the 1990s: a global analysis. En: P. Norris. 1999: 31-56.

El propósito de este artículo es hacer un mapeo de los patrones $y$ formas de apoyo ciudadano en poco más de sesenta sistemas políticos democráticos y semidemocráticos de Europa oriental y occidental, Asia, África, el continente americano y Oceanía, estos concentran un poco menos de la mitad de la población mundial. Con base en los datos de la EMV, el Latinobarómetro, el Central and Eastern Eurobarometer, el autor analiza el comportamiento de tres variables centrales de la cultura y el apoyo políticos: la comunidad política, la democracia como forma ideal de gobierno y el funcionamiento del régimen.

33. H.D. Klingemann \& D. Fuchs (eds.). Citizens and the State. New York. Oxford University Press, 1998, 474 p.

Esta obra, primer volumen de la serie Beliefs in Government auspiciado por la European Science Foundation, examina las relaciones cambiantes entre ciudadanos y Estado en las democracias de la Europa occidental. El libro se compone de tres partes: el ciudadano participante (parte 1), los intermediarios políticos (parte 2) y ciudadanos y sistema político (parte 3). La primera parte indaga la participación electoral (cap. 2) y no electoral (cap. 3); la segunda (caps. 4-8) reconstruye la relación ciudadanos, partidos políticos y organizaciones no partidistas. La tercera parte aborda las relaciones ciudadanos-sistema político con base en cuatro proposiciones: el apoyo creciente a los valores democráticos y el declive de la confianza y el apoyo al sistema democrático, las instituciones gubernamentales y los políticos. Ola Listhaug (cap. 9) examina la dinámica del apoyo a los políticos en cuatro países: Dinamarca, Noruega, Suecia y Holanda. Ola Listhaug \& Matti Wiberg (cap. 10) analizan los patrones de confianza ciudadana en las instituciones políticas y privadas más importantes en catorce países durante la década de los ochenta. Dieter Fuchs, Giovanna Guidorossi \& Palle Svensson (cap. 11) revisan las tendencias y cambios de una dimensión del apoyo político: la satisfacción 
con el funcionamiento del sistema democrático en catorce países europeo occidentales en los quince años comprendidos entre 1976 y 1991. Gabor Toka (cap. 12) compara la evidencia empírica de dos dimensiones del apoyo político: el funcionamiento de la democracia y el apoyo al régimen político en cuatro países de la Europa central y oriental. Por último, Jacques Thomassen dirige su atención a dos cuestiones: formular una operacionalización "más refinada" (p. 383) de los valores democráticos y evaluar el desarrollo del apoyo político en los años ochenta en doce países.

34. A. Kornberg \& H. Clarke. Citizen and Community: political support in a representative democracy. New York. Cambridge University Press, 1992, 285 p.

Este libro describe sistemáticamente $y$ analiza en profundidad, el apoyo político —es decir, las orientaciones afectivas- del "ciudadano promedio" a las estructuras y procesos políticos (p. 21) en una democracia representativa: Canadá. A partir de la formulación clásica de David Easton, los autores analizan el apoyo político en tres niveles: la comunidad política, el régimen político y las autoridades. Los datos empíricos provienen de varias bases de datos; entre otros, el Political Support Surveys (19831989), el National Elections Surveys (1974-1984), el Quality of Life (1977-1981) y el Eurobarómetro. La exposición inicia con la revisión de una gama de creencias acerca de la economía y la sociedad (cap. 2) y el examen de "las orientaciones psicológicas" (p. 61) hacia el sistema político: los significados ciudadanos de democracia, la identificación partidista, las evaluaciones del rendimiento gubernamental y las percepciones políticas sobre los ciudadanos (cap. 3). El siguiente capítulo constituye el eje del libro: el apoyo político (19741988) y sus correlatos (como son la socialización política, la efectividad gubernamental, la confianza y la eficacia política, etc.). Los dos capítulos que siguen refieren a la desafección política regional en Quebec y el occidente canadiense (cap. 5) $y$ las relaciones entre procesos electorales a nivel nacional y apoyo (cap. 6). El último capítulo plantea un modelo multivariado de las causas y consecuencias del apoyo político.
35. M. Kuechler. The dynamics of mass political support in Western Europe: methodological problems and preliminary findings. $\mathrm{K}$. Reif \& $\mathrm{R}$. Inglehart. 1991, Xxx.

36. J. Linde \& J. Ekman. "Satisfaction with democracy: a note on a frequently used indicator in comparative politics". European Journal of Political Research 42 (3). 2003: 391-408.

Los autores hacen una revisión crítica de un indicador utilizado extensamente, en el estudio del apoyo político: la "satisfacción con el rendimiento o funcionamiento del sistema democrático". A partir de la pregunta ¿qué mide este ítem?, el artículo operacionaliza el concepto y evalúa varios estudios empíricos sobre el apoyo a los principios democráticos $y$ el funcionamiento del sistema democrático. Según los autores, el ítem "funcionamiento del sistema democrático" no es un indicador de apoyo al sistema democrático o a los principios democráticos; e incluso está lejos de medir "la satisfacción con la forma en que trabaja la democracia” (p. 405).

37. O. Listhaug. The dynamics of trust in politicians. Klingemann \& Fuchs. 1998: 261-297.

38. W. Mayer. The Changing American Mind: how and why american public opinion changed between 1960 and 1988. Ann Arbor. The University of Michigan Press, 1993, $505 \mathrm{p}$.

Este libro nos ofrece una historia analítica de la opinión pública estadounidense durante los treinta años comprendidos entre 1960 y 1988: cómo y porqué cambió y qué diferencias han generado esos cambios en la política nacional de los Estados Unidos (p. 4). El libro está estructurado en dos partes, doce capítulos y cuatro anexos. La primera, compuesta por seis capítulos, describe los principales cambios que experimentó la opinión pública en campos tan vastos y diversos como el social y cultural, la política interna y externa, la economía, etc. La 
segunda parte compuesta por cinco capítulos, examina las diversas explicaciones teóricas: el reemplazo generacional (cap. 7), el cambio sociodemográfico (cap. 8), el impacto de las acciones gubernamentales, los procesos políticos y las cuestiones sociales con efectos políticos (cap. 9), y los efectos de los medios de comunicación (cap. 10). El último capítulo de cada una de las dos partes, ofrece un cuadro panorámico del cómo (cap. 6) y el porqué (cap. 11) cambió la opinión pública. El libro incluye cuatro apéndices: el primero (p. 343-355) es una guía de la fuente de datos; los otros tres (p. 357-493) reportan las preguntas y respuestas que constituyeron la base del análisis elaborado en los capítulos 3, 4 y 5; los cuadros son clasificados en cincuenta diferentes temas.

39. P. McDonough, S. Barnes \& A. López Pina. The Cultural Dynamics of Democratization in Spain. Ithaca. Cornell University Press, 1998, 241 p.

Este libro estudia a los "ciudadanos españoles durante su viaje de la era de Franco a la democracia política" (p. ix). El análisis centra su atención en dos ejes: la dinámica cultural de la democratización - es decir, los cambios en el capital social, el capital simbólico y el estilo cognitivo-y la transformación de la cultura política, caracterizada por la despolarización política o la "hegemonía de la moderación", la legitimidad democrática, la confianza institucional, las debilidades de la participación política, en suma, la "cultura del compromiso". Los datos provienen de cuatro encuestas nacionales - con una muestra aproximada de 3000 entrevistados cada una - realizadas en 1978, 1980, 1984 y 1990. El libro inicia con el análisis teórico de la legitimidad política (cap. 1), la revisión de las mediciones convencionales, la construcción de un modelo analítico y el examen de cómo las "configuraciones demográficas y culturales" (p. 41) influyen sobre la legitimidad (cap. 2). Los capítulos siguientes documentan $y$ analizan los cambios en la "agenda de la opinión pública" y los correlatos de la popularidad gubernamental (cap. 3); las particularidades de la opinión pública durante el gobierno del PSOE (cap. 4); y las consecuencias políticas — todavía inciertas (p. 130) - de algunos factores como son las identidades, las subculturas y las ideologías sobre el partidismo (cap. 5). El capítulo seis centra su atención en una dimensión central de la cultura democrática: la participación política; según los autores, los modos revelan una participación social y política "baja y modesta" (p. 146). Las conclusiones destacan la transformación de la cultura española que se resume en la moderación política de las masas.

40. A. Miller, W. Reisinger \& V. Hesli (eds.). Public Opinion and Regime Change: the new politics of post-soviet societies. Boulder-Col. Westview Press, 1993, 310 p.

41. J.R. Montero \& L. Morlino. "Legitimidad $y$ democracia en el sur de Europa". Revista Española de Investigaciones Sociológicas 64. 1993: 7-40.

Este artículo plantea dos interrogantes: ¿en qué medida estaban legitimadas las democracias del sur de Europa en los años ochenta? y ¿cuáles son las características distintivas de esa legitimidad? Montero \& Morlino inician el análisis con una discusión teórica del concepto legitimidad; después, pasan al examen de las actitudes ciudadanas en tres países del sur de Europa: España, Grecia y Portugal. La búsqueda se refiere a las inclinaciones ciudadanas hacia la democracia como régimen político, las experiencias autoritarias del pasado y la satisfacción con el funcionamiento real de la democracia. La última parte inspecciona algunas orientaciones generales hacia la política como el interés político, la alienación política, etc.

42. L. Morales. Instituciones, movilización y participación politica: el asociacionismo político en las democracias occidentales. Madrid. Centro de Estudios Políticos y Constitucionales, 2006, 397 p.

Este libro plantea una interrogante: ¿cómo explicar el asociacionismo político y sobre todo, cómo explicar la gran variación en los niveles de asociacionismo político que se encuentra en las democracias occidentales? La exposición plantea primero, una revisión sistemática y crítica de las propuestas teórico-metodológicas 
disponibles para el estudio de la participación política; segundo, un examen empírico de la participación y más particularmente, del asociacionismo político en 17 democracias occidentales: quince europeas (Alemania occidental, Austria, Bélgica, Dinamarca, España, Finlandia, Francia, Gran Bretaña, Grecia, Holanda, Irlanda, Italia, Luxemburgo, Portugal y Suecia), Canadá y los Estados Unidos; $y$ tercero, evalúa las evidencias disponibles. El análisis empírico de los modelos dominantes —el individual y contextual - puso "de manifiesto la enorme importancia del contexto sociopolítico para explicar porqué los ciudadanos de algunas democracias occidentales participan en política a través de organizaciones y porqué no lo hacen los de otras sociedades similares" (pp. 337-338). Según Morales, dos dimensiones son centrales en el contexto político: la estructura de oportunidades políticas y las pautas y estructuras de movilización sociopolítica (caps. 5 y 6).

43. M.L. Morán \& J. Benedicto. La cultura política de los españoles: un ensayo de reinterpretación. Madrid. Centro de Investigaciones Sociológicas, 1995, 139 p.

Según Morán \& Benedicto, este libro presenta "los resultados de un análisis empírico de los rasgos fundamentales de la CP de la sociedad española, así como de las líneas de continuidad y cambio que se detectan" en las dos primeras décadas de la transición y consolidación democrática. Los datos utilizados provienen de las encuestas realizadas por el Centro de Investigaciones Sociológicas de Madrid, entre 1980 y 1990. El libro se compone de tres capítulos: el primero revisa las aportaciones y limitaciones de la propuesta clásica, es decir, el modelo de la cultura cívica propuesto por Almond \& Verba; el segundo plantea un esquema multidimensional de la CP fundado en cuatro dimensiones - el individuo-ciudadano como actor, la vinculación ciudadano-política, la imagen del sistema político y los resultados de la acción institucional-y once variables. El tercer capítulo - eje de la obra- presenta el análisis longitudinal de los cuatro ejes temáticos (pp. 37-134). El primer eje temático, las tendencias valorativas básicas (pp. 38-54), subraya dos cuestiones: las imágenes y representaciones de la sociedad y las creencias políticas fundamentales: eficacia y competencia ciudadana. El segundo eje, la vinculación ciudadano-político (pp. 55-88), ahonda en el interés político, el conocimiento y la información política y las actividades políticas de los ciudadanos. El tercero, las imágenes del sistema político (pp. 88-126) aborda dos cuestiones: la legitimidad $y$ efectividad del sistema político. El último eje temático, los resultados de la actuación del sistema político (pp. 126-134), analiza la evaluación ciudadana de los outputs del sistema político.

44. N. Nevitte (ed.). Value Change and Governance in Canada. Toronto. University of Toronto Press, 2002, 218 p.

Este obra colectiva, escrita por politólogos y psicólogos sociales de varias universidades canadienses, analiza diversas facetas de la relación entre el cambio de valores y la reorientación de las relaciones ciudadanoEstado. Según los autores, un conjunto de cambios estructurales - como son la creciente riqueza social, el aumento acelerado de los niveles educativos y la expansión de las clases medias - han estimulado cambios significativos en las orientaciones valorativas y a su vez, estos cambios han modificado las visiones ciudadanas de la democracia, el gobierno, las legislaturas, etc. El libro se compone de seis capítulos. El primero plantea una visión general de los dos ejes analíticos. Los otros capítulos analizan distintos aspectos de la problemática. Richard Nadeau estudia la satisfacción ciudadana con el funcionamiento del sistema; Mebs Kenji analiza el descontento político y las preferencias electorales; Lisa Young plantea una explicación alternativa al creciente desencanto con la vida democrática: según la autora, el debilitamiento del capital social erosiona una de las bases de sustento del gobierno democrático; Neal Roese muestra los efectos de la eficacia ciudadana y el activismo político en el declive de la confianza ciudadana en el gobierno federal; por último, David Docherty revisa las actitudes hacia uno de los actores políticos: los congresistas. 
45. P. Nevitte. The Decline of Deference. Ontario-Canadá. Broadview Press, 1996, $369 \mathrm{p}$.

El autor explora el cambio en las orientaciones valorativas de la sociedad canadiense en la década 1981-1990. El análisis centra su atención en tres dimensiones: los valores políticos (parte 2, caps. 3 y 4), los valores económicos (parte 3, caps. 5 y 6) y las relaciones primarias (parte 4, caps. 7 y 8). La información procede de la Encuesta Mundial de Valores (EMV) 1981 y 1990. Esta base de datos permitió pasar el análisis del caso canadiense al análisis comparativo del cambio de valores con los Estados Unidos y diez países europeos. Desde la perspectiva de la $\mathrm{CP}$, Nevitte examina dos cuestiones. La primera refiere a los cambios experimentados en un conjunto de variables centrales de la cultura política (cap. 3) como son el interés político, la confianza en las instituciones gubernamentales $y$ no gubernamentales $y$ la comunidad política (Easton) o "cosmopolitanismo" (Nevitte, p. 63). La segunda revisa los cambios producidos en los patrones de participación política (cap. 4) que se expresan en la aparición de una conducta ciudadana de protesta (pp. 77-83) la emergencia de nuevos movimientos sociales como el ambientalismo (pp. 84-97), y la presencia de nuevas orientaciones $y$ actitudes hacia el cambio y el sistema de autoridad política. En suma, dice el autor, el aumento en el interés y la información política, el declive en la confianza en las instituciones gubernamentales y no gubernamentales, el nivel creciente del potencial de protesta ciudadana y la extensión de nuevos movimientos sociales apuntan a la presencia de "cambios fundamentales" en los valores políticos (p. 104) y la cultura política (p. 94) de la sociedad canadiense.

46. H.J. Nielsen. "The uncivic culture: attitudes towards the political system in Denmark and the vote for the Progress Party". Scandinavian Political Studies 11. 1976: 147-156.

47. P. Norris (ed.). Critical Citizens: global support for democratic government. New York. Oxford University Press, 1999, 303 p.
Critical Citizens es un análisis sistemático de los patrones globales de apoyo o "desapoyo" político en los sistemas democráticos en transición, en proceso de consolidación y las ya establecidas, en los finales del siglo veinte. El capítulo introductorio, escrito por Pippa Norris, construye un esquema de las teorías sobre la crisis de la democracia, el marco conceptual y la medición del apoyo político y una síntesis de las teorías explicativas. El libro se compone de tres partes y trece capítulos. La primera parte articula tres capítulos: Hans-Dieter Klingemann revisa los patrones $y$ formas de apoyo político a nivel mundial en los años noventa, Russell Dalton y William Mishler \& Richard Rose discuten el apoyo en las democracias industrial avanzadas y en siete países de la Europa post-socialista respectivamente. La segunda parte analiza tres experiencias nacionales: la confianza política en Suecia (cap. 5), la actitudes democráticas en la Alemania unificada (cap. 6) y las tensiones entre ideal y realidad democrática en Corea del Sur (cap. 7). La tercera parte discute las explicaciones más plausibles del declive en el apoyo institucional: la confianza social y política (cap. 8), el rendimiento gubernamental (caps. 9 y 10), las explicaciones institucionales (cap. 11) y el cambio de valores (cap. 12). Las conclusiones (cap. 13) subrayan que la evidencia reportada en esta obra colectiva sugiere el crecimiento de un nuevo tipo de ciudadano: el ciudadano crítico

48. J. Nye, P. Zelikow \& D. King (eds.). Why People Don't Trust Government. Cambridge-Mass. Harvard University Press, 1998, 339 p.

Este libro colectivo examina "los síntomas más obvios del descontento - las expresiones de desconfianza pública en y la insatisfacción con el gobierno" (p. 254). El análisis centra su atención en la experiencia del "gobierno nacional" estadounidense. El libro está estructurado en tres partes: la primera discute la esfera de acción (cap. 1) y el rendimiento o eficiencia gubernamental (cap. 2). La segunda revisa "el menú" explicativo o mejor dicho, las explicaciones más influyentes de la desconfianza e insatisfacción ciudadana con el gobierno nacional. Robert Lawrence revisa las causas 
económicas (cap. 4), Jane Mansbridge destaca que las causas socioculturales más importantes (cap. 5) de la desconfianza derivan probablemente, de las grietas sociales y culturales que ha experimentado el país desde 1960 (p. 150), y David King centra su atención en la polarización de los partidos políticos (cap. 6). La tercera y última parte presenta descripciones $y$ análisis de las actitudes públicas: Robert Blendon revisa las actitudes cambiantes de la población adulta estadounidense (cap. 8), Ronald Inglehart compara las tendencias hacia la erosión de la autoridad institucional en 21 países durante la década 1981-1990 (cap. 9) y Susan Pharr analiza las particularidades de la confianza y las orientaciones políticas en la sociedad japonesa (cap. 10).

49. G. Patrick "Political culture". G. Sartori (ed.). Social Science Concepts: a systematic analysis. Beverly Hills. Sage, 1984: 265-314.

50. S. Pharr \& R. Putnam (eds.). Disaffected Democracies. New Jersey. Princeton University Press, 2000, 362 p.

51. D. Pollack; J. Jacobs, O. Muller \& G. Pickel. Political Culture in Post Communist Europe. Aldershot-GB: Ashgate, 2003.

52. T. Poguntke \& S. Scarrow (eds.). "The Politics of Anti-Party Sentiment". Número especial de European Journal of Political Research 29 (3). 1996.

Este número monográfico reune siete trabajos dedicados al estudio de una temática reciente: los sentimientos antipartidistas de las elites y las masas en el contexto europeo. En términos generales, estos sentimientos no son nuevos; según Piero Ignazi (pp. 279-296) y Susan Scarrow (pp. 297-317) estos sentimientos tienen en los países europeos, una larga y prestigiada tradición intelectual que se vincula con la desconfianza $y$ hostilidad hacia los partidos en tanto que canales de representación política. Thomas Poguntke y Luciano Bardi analizan las mediciones empíricas de este sentimiento $y$ muestran su mayor visibilidad; mientras el primer autor revisa la experiencia en trece democracias occidentales, el segundo aborda la experiencia italiana. Los dos últimos trabajos examinan el sentimiento apartidista $y$ antipartidista en el Reino Unidos y el antipartidismo en los Estados Unidos y el apoyo al candidato Ross Perot en las elecciones presidenciales de 1992.

53. K. Reif \& R. Inglehart (eds.). Eurobarometer: the dynamics of european public opinion. NYC, St. Martin's Press, 1991, $392 \mathrm{p}$.

Esta obra colectiva es un homenaje a Jacques-Rene Rabier -fundador y director del Eurobarómetro, desde sus inicios en los años setenta hasta fines de 1986. Escrito por veinticuatro reconocidos estudiosos de siete países de ambos lados del Atlántico, el libro se compone de veintidós capítulos que analizan varias dimensiones del cambio sociocultural y político de los países miembros de la Comunidad Europea, recogidos en las encuestas bianuales del Eurobarómetro. El primer capítulo, escrito por los editores, examina la contribución del Eurobarómetro al estudio del cambio social $y$ político y revisa algunas tendencias del giro valorativo. Marita Inglehart (cap. 9) discute las diferencias de género en las actitudes hacia la familia, los centros de trabajo y la política; el análisis longitudinal del interés político, realizado por Jan van Deth (cap. 10), cuestiona la hipótesis del creciente interés político (p. 211). Cuatro capítulos están dedicados a los partidos y sistemas electorales: Russell Dalton (cap. 12) explora la dinámica del cambio electoral en los sistemas de partidos, Samuel Barnes (cap. 13) indaga la "persistencia" electoral de los partidos de derecha y Mark Franklin \& Thomas Mackie (cap. 14) y Cees van der Eijk (cap. 15) exploran la utilidad del Eurobarómetro en el estudio comparado del cambio electoral. Manfred Kuechler (cap. 16) compara el apoyo de masas a los sistemas políticos y discute los problemas conceptuales y metodológicos de la medición del apoyo político realizado por el Eurobarómetro. Richard Katz (cap. 17) compara valores y actitudes de materialistas $y$ posmaterialistas $y$ muestra que no se trata de diferentes puntos de vista sino mundos valorativos distintos. 
54. R. Rohrschneider. Learning Democracy: democratic and economic values in Unified Germany. New York. Oxford University Press, 1999, 309 p.

Este libro compara los valores ideológicos de los alemanes después de la caída del Muro de Berlin y la unificación; más específicamente, examina las relaciones entre instituciones, valores ideológicos y apoyo ciudadano a las instituciones políticas. Empíricamente, el autor busca determinar qué tan diferentes son los valores ideológicos de las élites y las masas alemanas de "occidente" y "oriente" después de la unificación. El segundo capítulo plantea la perspectiva teórica del "aprendizaje institucional" y el tercero revisa la experiencia histórica del aprendizaje institucional (1945-1989). El análisis empírico centra su atención en los ideales democráticos (cap. 5), la tolerancia política (cap. 6), el pluralismo (cap. 7) y los valores económicos (cap.8). Con base en este análisis, Rohrschneider aborda la relación entre los valores ideológicos y el apoyo institucional (cap. 9); la discusión se desarrolla en tres pasos; el primero es teórico y se resume en una pregunta: ¿por qué los ciudadanos apoyan las instituciones democráticas?, el segundo revisa la confianza de las élites y las masas en las instituciones democráticas, y el tercero discute los determinantes de la confianza institucional entre las élites y las masas de la ex Alemania oriental. Los datos provienen de dos encuestas aplicadas a los parlamentarios alemanes entre octubre 91-junio 92 y noviembre 94-abril 95 así como de varias encuestas aplicadas a muestras nacionales.

55. R. Rose. "Medidas de democracia em surveys". Opiniao Pública 1. 2002: 1-29.

56. R. Rose, W. Mishler \& Ch. Haerpfer. Democracy and its alternatives: understanding post-communist societies. Baltimore. The Johns Hopkins University Press, 1998, $270 \mathrm{p}$.

Este libro es un análisis de las "sociedades post comunistas"; más particularmente, examina la dirección que toma la opinión pública ante el shock que significó la caída del socia- lismo y el inicio de una nueva etapa basada en la economía de mercado y la democratización política. El libro se compone de dos partes. La primera es de naturaleza teórica y refiere a la definición de democracia y las alternativas no democráticas en la perspectiva de la "hipótesis Churchill" (cap. 2), las múltiples alternativas y rutas que tienen los procesos de cambio de régimen político (cap. 3). La segunda parte analiza las respuestas de las masas a la transformación política; los datos proceden de las encuestas del New Democracy Barometer III recogidas por la Paul Lazarfeld Society de Viena-Austria, en nueve sociedades post-comunistas: Bulgaria, República Checa, Hungría, Polonia, Rumania, Eslovaquia, Eslovenia, Belorusia y Ucrania, entre noviembre de 1993 y abril del 94. Los valores y creencias políticas y económicas de las masas son analizados en cuatro capítulos: el quinto compara las evaluaciones ciudadanas sobre el viejo régimen y los niveles de satisfacción e insatisfacción con la nueva democracia, el sexto analiza el impacto de la estructura social sobre el apoyo al nuevo régimen político, el séptimo discute "el presente a la luz del legado del pasado" (p. 146), el octavo centra su atención en la influencia de las condiciones macro y micro económicas sobre las actitudes políticas. El siguiente capítulo analiza la influencia particular y combinada de los contextos políticos y económicos, la estructura social y los atributos individuales en la explicación del apoyo al régimen político.

57. D. Shin. Mass Politics and Culture in Democratizing Korea. New York. Cambridge University Press, 1999, 335 p.

58. J.L. Sullivan, J. Pierson \& G. Marcus. Political Tolerance and American Democracy. Chicago. The University of Chicago Press, 1982, 278 p.

Este libro analiza "la tolerancia hacia los grupos políticos extremistas" en la opinión pública norteamericana (p. 2). Según los autores, la tolerancia política existe cuando los individuos reconocen los derechos ciudadanos de aquellos individuos y grupos que no piensan igual que ellos (pp. 76-81). El libro se compone 
de nueve capítulos. Los tres primeros son teóricos y metodológicos: el primero (pp. 1-25) define el concepto y establece los límites de la tolerancia, el segundo (pp. 26-53) hace una revisión crítica de la literatura empírica más influyente publicada entre 1955 y 1978 —como son entre otras, las aportaciones de Samuel Stouffer, Prothro \& Grigg, McClosky - y el tercero (pp. 54-81) compara los resultados del estudio clásico de Stouffer (1955) y del NORC (1977) y construye con base en este último estudio, un perfil de la tolerancia política en los Estados Unidos de los años setenta. Los tres capítulos siguientes analizan los datos de la encuesta nacional realizada por el National Opinion Research Center (NORC) en 1978. Los autores exploran las fuentes sociales (cap. 5), psicológicas (cap. 6) y las "variables políticas [...] relacionadas con la tolerancia" (cap. 7). Con esta base, Sullivan y colaboradores formulan un modelo multivariado para el análisis de la tolerancia política (cap. 8). El último capítulo resume los hallazgos centrales de la investigación.

59. M. Torcal \& J.R. Montero. Political Disaffection in Contemporary Democracies: Social Capital, Institutions and Politics. Londres: Routledge, 2005.

60. J.M. Torcal, J.R. Montero \& R. Gunther. "Ciudadanos y partidos en el sur de Europa: los sentimientos antipartidistas". Revista Española de Investigaciones Sociológicas 101. 2003: 9-48.

Este artículo explora las actitudes antipartidistas de los ciudadanos, un supuesto rasgo de las democracias occidentales tan frecuentemente referido como escasamente estudiado. En el análisis empírico de cuatro países del sur de Europa, los autores reportan que las orientaciones antipartidistas presentan dos dimensiones. La primera, el antipartidismo "reactivo" parece cambiar en respuesta a circunstancias políticas coyunturales; la segunda, el antipartidismo "cultural" está caracterizado por su estabilidad y su vinculación con bajos niveles educativos y de información política. Mientras el antipartidismo reactivo no tiene implicaciones actitudinales o participativas significativas, el cultural parece formar parte de un síndrome más amplio de desafección política.

61. P. Ulram \& F. Plasser. Political culture in East-Central and Eastern Europe: empirical findings 1990-2001. D. Pollack. 2003: 31-46.

62. P. Waldron-Moore. "Eastern Europe at the crossroads of democratic transitions: evaluating support for democratic government and consolidation of democratic regimes". Comparative Political Studies 1. 1999: 32-62.

La autora explora el apoyo de masas a las instituciones democráticas, la satisfacción con el gobierno democrático y los vínculos de esta con el apoyo político en seis países ex socialistas: Hungría, Lituania, Polonia, Rusia, Ucrania y la República Checa. En términos generales, los datos del Central and Eastern Eurobarometer 1992 reporta que los entrevistados que apoyan el sistema democrático son de una parte, los desencantados con el viejo sistema socialista $y$ de otra, los que favorecen el cambio político y económico.

63. J. Wright. "Political disaffection". S. Long. The Handbook of Political Behavior 4. New York. Plenum, 1981: 174.

Este artículo hace una revisión exhaustiva de la bibliografía teórica y empírica sobre un concepto confuso y ambiguo (p. 17): desafección, alienación o descontento político. La primera parte revisa la teoría de la alienación; la segunda, basada en la bibliografía teórica y empírica disponible, discute la conceptualización y medición de la alienación política, examina sus correlatos socio-demográficos, culturales y políticos; $y$ revisa sus tendencias —es decir, la de los años setenta-y explicaciones. La tercera parte analiza los correlatos actitudinales y comportamientos de la alienación política. Según el autor, hay poca evidencia de que la alienación política en cualquiera de sus formas y manifestaciones, pueda constituir una amenaza para la estabilidad de los regímenes democráticos (p. 70). 
64. H. Yee. The Political Culture of China's University Students: a comparative study of university students in Mainland China, Hong Kong, Macau and Taiwan. New York. Nova Science Publishers Inc. 1999, 189 p.

En la perspectiva clásica de Almond \& Verba, este libro analiza la cultura política de los universitarios chinos; más particularmente, compara las subculturas políticas de los universitarios chinos y sobre todo, explora la existencia de una "cultura cívica" en el mundo universitario, "condición necesaria para una democracia estable" (p. 141). El análisis se basa en las encuestas recogidas entre 3695 estudiantes de los Departamentos de Ingeniería y Ciencias Naturales, Humanidades y Ciencias Sociales y Ciencias Sociales Aplicadas en diez universidades de China continental, dos de Hong Kong, una de Macau y otra de Taiwan. El libro está organizado en nueve capítulos; el análisis empírico de la cultura política se desarrolla en cinco capítulos: el tercero estudia las orientaciones $y$ actitudes cognitivas, evaluativas $y$ afectivas hacia el sistema político; el cuarto examina dos cuestiones: de un lado, la identidad $y$ el orgullo nacional $y$ de otra, la "conciencia de nacionalidad" (p. 67) o sentimientos patrióticos; el quinto evalúa un "componente importante" (p. 80) de la cultura política: la conciencia democrática es decir, los valores democráticos, el rendimiento gubernamental y la identificación con el socialismo; el sexto mide las actitudes hacia la participación política; $y$ el séptimo analiza el papel de la familia como agente de la socialización política. El último capítulo resume los hallazgos del estudio. 
